\title{
Design and Construction of a Melon Dehusking Machine
}

\author{
E. J. Udom and B. B. Okon \\ Department of Mechanical Engineering, Sustainable Infrastructure Services Group, Akwa Ibom State University, PMB 1167, Uyo, \\ Nigeria
}

\begin{abstract}
Melon dehusking is often associated with lots of manual labour and stresses. In order to reduce the stress and boredom usually involved in manual dehusking of melon process, a melon dehusking and separation machine was designed, constructed and tested for operation as presented in this paper. The melon dehusking machine operates on the principle of attrition/friction as opposed to the use of an impact force in the dehusking chamber for shelling of melon seeds. This principle results in minimum seed breakage thus, reduces the amount of wastage involved in the mechanized processing of the melon seeds oil. Also, this machine architecture consists of a separation chamber which utilizes the air generated from a centrifugal blower in an attempt to separate the broken shells of melon from its whitish inner cotyledon immediately after the dehusking process. Other components of this machine include: the feed hopper, dehusking chamber and the power unit. This melon dehusking machine operates at the optimal dehusking speed of $1,400 \mathrm{rpm}$, feed rate of $11 \mathrm{~kg} / \mathrm{hr}$ and a shelling efficiency of about $85 \%$. The effect of the moisture content of melon seeds regarding the shelling performance was considered and the result showed that a soaking time of 8 minutes and a spreading time of 30 minutes yield good optimal dehusking process.
\end{abstract}

Key words: Agriculture, food processing, mechanization, melon, invention.

\section{Introduction}

Nigeria is an agricultural nation. Melon (citrullus vulgaris) is widely cultivated in Nigeria among other seedlings during the planting season yearly. Several tonnes of melon seeds are gathered each harvesting period but only a very small percentage of the total harvest are dried by atmospheric draught and bagged for storage. A high percentage of waste is usually incurred in melon seeds processing due to lack of good processing and storage facilities [1, 2]. Melon seeds when properly processed yield a lot of by-products, which could be used as food, feed or as raw materials for the small, medium and large scale industrial manufacture outputs [1]. Additionally, melon seeds are highly enriched with oil, and it has about $45 \%$ of oil content. After the extraction of oil from melon seeds, the remaining part [2] noted that it can still be used as food for human consumption or as an additive in agro-feed for industrial processes.

Corresponding author: B. B. Okon, $\mathrm{PhD}$, senior lecturer, research field: sustainable infrastructure services. emails: engrvik@gmail.com, engrvik@yahoo.com
Further processing associated with melon seeds is that it can be grounded and used as thickener or binder in the chemical and pharmaceutical industry [2]. The outer shell of the melon seed when properly harvested in a large quantity can equally be used in the preparation of agricultural feed. The shell has about (12-55) $\mathrm{MJ} / \mathrm{kg}$ calorific value and hence can be used as a source of energy for industrial use [2]. The major problems encountered in the processing of melon seeds are the removal of the yellow outside shell and the separation of the broken shells from the white seeds. Locally, in the current situation, manual method is being used for the commercial dehusking and separation of melon seeds.

Also, the little mechanized approach available presently is not efficient because the melon seeds are broken and no longer uniform upon removal from the dehusking machine. Therefore, an efficient and mechanized method of dehusking and separation processes is capable of increasing productivity, reducing processing time and bringing down human labour input to the nearest minimum [1,2]. These 
problems arising from the manual dehusking and separation of the melon whitish seeds from the shells necessitated the idea of design, construction of an efficient melon dehusking and separation machine for our local communities and industries [3, 4].

Melon is processed in different quantity, depending on the form of consumption. For domestic consumption that is for the preparation of melon soup, it will be in small quantity and for commercial consumption in large quantity. Commercial processing of melon seeds [4] observes that is always very tedious when it is done manually (by hand) desiring the mechanized processing methods, that is, the use of a dehusking and separation machine. However, local consumers of melon in recent times tend to prefer melon seeds that are manually processed to those from the mechanized approach. The general complaint is always that the melon seeds that are processed by machines are always broken into smaller pieces and not uniform and thus a high percentage of waste usually occurred.

These inclination researchers [1-4] uphold that it is as a consequent of incessant breakages associated with the use of melon dehusking machine that consumers prefer the manual method. Another argument from the consumers is that, due to frictional forces experienced in the machine during the dehusking process, this melon seeds often change in colour and are no longer fresh as compared to those ones that are processed manually [1-3]. But to what extent can the demand for this product meet daily the supply? Since, the feedback here is not positive, then, the mechanized approach option is most desirable

\section{Mechanized Melon Dehusking Option}

Agricultural mechanization operation is of age and a lot of work has been done to make the operation easier in different post harvesting processing. An attempt was made on melon seed shelling [8] where the seeds were shelled by moving between vanes on a rotating impeller and making an impact on a fixed cylindrical ring. Here, the bending properties of the melon seeds when compressed between two parallel plates under static loading were studied but the outcomes contain some gaps for continuous research and development.

A similar attempt was made [1] using the same principle of impacting but on a stationery abrasive cylinder. In applying this principle, a melon sheller with rotating impeller vanes was designed with the angle of release, machine speed, and impact force of $30^{\circ}$ at $980 \mathrm{rpm}$ and $0.367 \mathrm{~N}$ respectively [6, 7].

The melon shelling machine so designed was made up of three sections, the hopper, shelling chamber which consists of the shelling disc and the shaft along with the gear system. The hopper was made of four welded mild steel metal sheets slanting towards a smaller opening. It had two openings that could hold a reasonable amount of unshelled melon seeds and the inlet throat connected the hopper to the shelling drum. The shelling chamber consisted of the shelling drum, the shelling vanes, the shelling disc and the spacer. The shelling drum was made from mild steel and the inner part of the drum was lined with rods, while the shelling disc was made from galvanized steel and had vane slots at the edges. The shelling vanes were made from galvanized sheet and were arranged side by side at an angle of $120^{\circ}$, the gear on the other hand was made from cast iron and was used to operate the machine manually [4-8].

Under this arrangement, the machine had a key connected to the shaft which could be easily disconnected when switching to an automatic operation of the machine. The bevel gear was used to transfer power from the driving shaft to the shelling section. The frame of the machine was the support on which the machine rested, that is it acted as a stand that supported both the shelling drum and the bevel gear. Another study [9] maintained that melon shelling using the principle of seed impacting on a stationary outer drum was to obtain an efficiency of about $47 \%$ through an angle of release, machine speed 
and impact force of $45^{\circ}, 1,530 \mathrm{rpm}$ and $0.537 \mathrm{~N}$ respectively.

From the forgoing, this study seeks to apply a rubbing action motion as opposed to the use of impact force to shell melon seeds. It further intends to solve the wastage and breakage challenges during processing as it incorporates a treatment process where the melon seeds will be submerged into water for a period of time in pursuit of optimal dehusking process.

\section{Methodology}

This study adopts various methods for analysis as presented. The literature review was aimed at studying previous researches associated with the melon dehusking processes and its operation. Other methods relating to machine design and construction applied in this paper are also indicated.

\section{Key Analysis Parameters}

The following analysis parameters were considered in the design and construction processes of the melon dehusking machine.

\subsection{Power Requirements}

The total power required by the machine for melon dehusking was calculated using models as specified [3]. Hence, Eq. (1) was applied in this analysis.

$$
\mathrm{P}_{\mathrm{T}}=\mathrm{P}_{\text {impeller }}+\mathrm{P}_{\text {shaft }}+\mathrm{P}_{\text {shelling }}
$$

$\mathrm{P}_{\text {shelling }}$ is negligible since the seeds are not resident in the sheller but flow through in pieces during the operation process. Then;

$$
\mathrm{P}_{\mathrm{T}}=\mathrm{P}_{\text {impeller }}+\mathrm{P}_{\text {shaft }}
$$

But, shaft and impeller are mechanically coupled together, so

$$
\mathrm{P}_{\mathrm{T}}=\mathrm{P}_{\text {impeller with shaft }}
$$

Analyzing further for the power requirement,

$$
\begin{aligned}
\mathrm{P}_{\text {impeller with shaft }} & =\mathrm{T}_{\text {impeller with shaft }} \\
& \times \mathrm{V}_{\text {impeller with shaft }} \\
\text { Similarly, } & \mathrm{V}_{\text {impeller with shaft }}=\frac{2 \pi N}{60} \mathrm{~m} / \mathrm{s}
\end{aligned}
$$

In this analysis, the following factors were considered, that is:

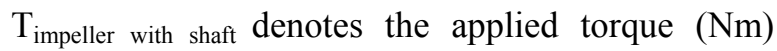
while $\mathrm{N}$ signifies the number of revolution per minute of the impeller with shaft set at $350 \mathrm{rpm}$.

Also,

$\mathrm{T}_{\text {impeller with shaft }}=$ mass $\times$ acceleration due to gravity

$$
\times \text { radial distance }
$$

For this type of analysis, standard figures were applied as follows according to Refs. [6, 7]. Thus;

- Mass $(\mathrm{m})=5.6 \mathrm{~kg}$

- Radial distance $(\mathrm{R})=0.095 \mathrm{~m}$ and

- Acceleration due to gravity $(\mathrm{g})=10 \mathrm{~m} / \mathrm{s}^{2}$

Then, for the computation of the torque related to the impeller with shaft, therefore;

$$
\begin{array}{r}
\mathrm{T}_{\text {impeller with shaft }}=5.6 \times 10 \times 0.095=5.32 \mathrm{Nm} \\
\text { So, } \mathrm{P}_{\text {impeller with shaft }}=\frac{5.32 \times 2 \times 3.142 \times 350}{60 \times 1000}
\end{array}
$$

Then, $\mathrm{P}_{\text {impeller with shaft }}=0.195 \mathrm{~kW} \approx 0.329 \mathrm{hp}$.

In this study, a factor of safety of 2 , for mild steel materials under static loading was considered and power required in this case was $0.66 \mathrm{hp}$. Therefore, an electric motor of $1 \mathrm{hp}$ was chosen to power the melon dehusking machine impeller, shaft and to shell the seeds during operation.

\subsection{Determination of Shaft Diameter}

The diameter of the solid shaft used in transmitting the rotary motion from the electric motor to the melon dehusking chamber was determined as follows:

For the optimal dehusking speed which was taken as $\mathrm{N}=350 \mathrm{rpm}$. Also, power required by the solid shaft was selected, thus;

- $\operatorname{Power}(\mathrm{P})=0.195 \mathrm{~kW}$

- Factor of safety (FOS) for mild steel under static loading $=2$

- Then, the ultimate shear stress for mild steel was taken as $360 \mathrm{Mpa}$.

But for the allowable shear stress in this analysis therefore,

$$
\tau=\frac{\tau u}{\mathrm{FOS}}
$$




$$
\tau=\frac{360}{2}=180 \mathrm{MN} / \mathrm{m}^{2}
$$

Torque transmitted by the shaft,

$$
T=\frac{P \times 60}{2 \pi \mathrm{N}}
$$

Evaluating Eq. (9) properly yields $=5.32 \mathrm{Nm}$ and given that torque transmitted by a solid shaft is guided by Eq. (10). In this situation,

$$
T=\frac{16}{16} \text { 火火 } \mathrm{d}^{3}
$$

And in any case,

$$
\begin{gathered}
\mathrm{d}^{3}=\frac{16 \mathrm{~T}}{\tau} \\
\text { Therefore, } \mathrm{d}^{3}=\frac{16 \times 5.32}{3.142 \times 180 \times 10^{6}}
\end{gathered}
$$

The solid shaft applied in this case was taken.

$\mathrm{d}^{3}=1.728 \times 10^{-6} ; \mathrm{d}=\sqrt[3]{1.728} \times 10^{-6}$ since, $\mathrm{d}=$ $0.01232 \mathrm{~m}$, then, this solid shaft diameter was suitably chosen as $\mathrm{d}=12 \mathrm{~mm}$. From the above analysis, a 12 $\mathrm{mm}$ diameter solid shaft was chosen for the dehusking chamber to transmit the rotary motion from the electric motor to the dehusking impeller.

\subsection{Machine Description}

The melon dehusking machine is made up of three sections namely: hopper, dehusking chamber, and power unit.

Hopper: This is a funnel shaped structure with a cavity through which melon seeds pass into the dehusking unit, it is made up of four welded mild steel sheets slanting towards a smaller opening. It has an upper dimension of $244 \mathrm{~mm} \times 244 \mathrm{~mm}$ and a cavity dimension of $54 \mathrm{~mm} \times$ $54 \mathrm{~mm}$.

Dehusking Chamber: It is where the dehusking process takes place and it consists of a rotating impeller with curved vanes and steel bars of the same thickness as the curved vanes attached to the impeller. The function of the rotating impeller is to impart a frictional (rubbing) force on the melon seeds and thus enable the dehusking of its shells.

Power Unit: It involves the power switch, cables and the electric motor that converts the electrical energy from the mains to the mechanical energy for the dehusking process. Design Procedure: The following procedures were adopted during the construction of this machine.

Mainframe Construction and Specification: The mainframe of this machine is the support on which all other machine components are mounted. The material used in its construction was hollow mild steel pipes. The hollow pipes were chosen for the reduction of machine weight. The dimensions of the mainframe are as follows: Height: $350 \mathrm{~mm}$; Length: $400 \mathrm{~mm}$; and the Width was selected as $400 \mathrm{~mm}$ respectively.

Inlet Hopper: The compartment is where the pretreated melons are loaded in the machine before it is introduced into the dehusking chamber. The hopper is mounted on the top of the machine such that its exit chute leads to the inlet channel of the dehusking chamber. The material used for the construction of the hopper was mild steel sheets and the dimensions of the hopper are as presented.

- Upper dimension: $200 \mathrm{~mm} \times 200 \mathrm{~mm}$

- Cavity dimension: $50 \mathrm{~mm} \times 50 \mathrm{~mm}$

Dehusking Chamber and Specification: This is the chamber where the actual dehusking of the melon seeds takes place. The components involved in this section include the impeller, impeller casing, impeller casing cover, bolts and nuts and electric motor. A $1 \mathrm{hp}$ electric motor was used to transmit rotary motion to the impeller by connecting a solid shaft from the electric motor to the impeller. The dimensions of the components of this chamber are as follows:

- Impeller diameter: $190 \mathrm{~mm}$

- Impeller casing diameter: $250 \mathrm{~mm}$

- Inlet channel: $50 \mathrm{~mm} \times 50 \mathrm{~mm}$

- Exit channel: $120 \mathrm{~mm} \times 70 \mathrm{~mm}$

- Electric motor rating: $1 \mathrm{hp}$

Dimensional Characteristics of Melon Seeds: In this study the various dimensional characteristics were considered. This involves measurement of physical characteristics of melon seeds for five dimensional quantities as displayed in Table 1. 
Table 1 Dimensional characteristics of seeds.

\begin{tabular}{ll}
\hline Parameter & Melon seeds \\
\hline Surface area $\left(\mathrm{m}^{2}\right)$ & 0.037 \\
Density $\left(\mathrm{kg} / \mathrm{m}^{3}\right)$ & 405 \\
Lengths $(\mathrm{m})$ & 0.020 \\
Thickness $(\mathrm{m})$ & 0.002 \\
Widths $(\mathrm{m})$ & 0.011 \\
\hline
\end{tabular}

\section{Results and Discussion}

In this research, the achievable results in each case are presented based on the applied analytical methods.

\subsection{Machine Performance Evaluation}

Some performance parameters of this machine were investigated which include the shelling efficiency, the likelihood of damaging seeds, and the critical spreading time. In the case of shelling efficiency, the effectiveness of the machine in terms of the number of seeds shelled was obtained using Eq. (13).

$$
\eta=\frac{W s u+W_{s b \times 100}}{W_{t}}
$$

Where,

$\eta$ is the shelling efficiency;

$W_{\text {su }}$ is the number of unbroken seeds shelled;

$W_{\mathrm{sb}}$ is the number of broken seeds shelled; and

$W_{\mathrm{t}}$ is the total number of seeds.

The application of model in Eq. (13) is shown in Fig. 1.

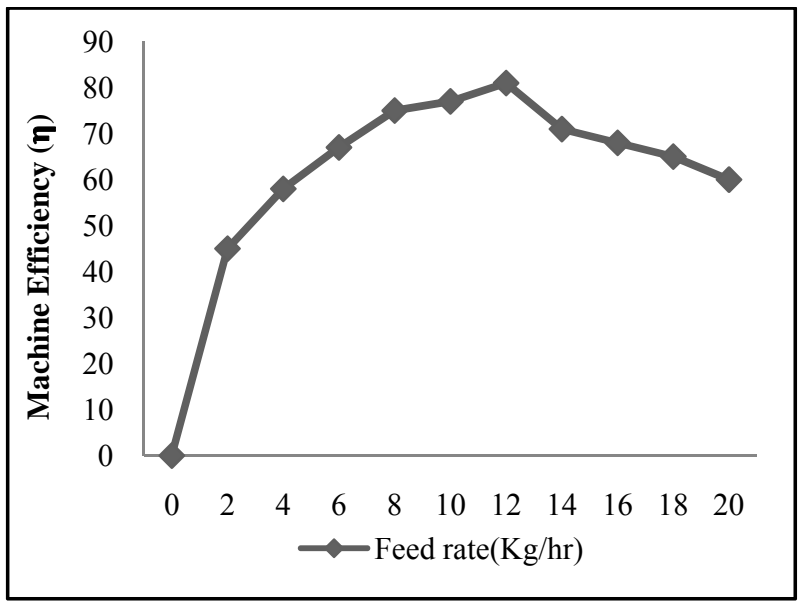

Fig. 1 Shelling efficiency against machine feed rate.
From Fig. 1, it is found that there is first an increase from $42-79 \%$ and then a decrease to $60 \%$ shelling efficiency, as the feed rate changes from $5 \mathrm{~kg} / \mathrm{hr}$ to $10.5 \mathrm{~kg} / \mathrm{hr}$ and then to $16.2 \mathrm{~kg} / \mathrm{hr}$. It is therefore observed that optimal shelling of the melon seeds occurs around $10.5 \mathrm{~kg} / \mathrm{hr}$.

\subsection{Likelihood of Damaging Seeds}

This was analyzed through Eq. (14) to determine the amount of damaged melon seeds during the dehusking process. Fig. 2 shows the outcome of the likelihood of damage seeds analysis.

$$
\eta_{\mathrm{b}}=\frac{W u b+W_{s b \times 100}}{W_{t}}
$$

Where,

$\eta_{\mathrm{b}}$ is the percentage of broken seeds;

$W_{\mathrm{ub}}$ is the number of unshelled broken seeds;

$W_{\mathrm{sb}}$ is the number of broken seeds that were shelled;

$W_{\mathrm{t}}$ is the total number of seeds.

In Fig. 2, findings show that the likelihood of seed damage expresses a different behavior that is, the trend line is lowest at the middle feed rate of $10.5 \mathrm{~kg} / \mathrm{hr}$. Thus, the results from Figs. 1 and 2 present strong conclusions with respect to optimal operation performance of the melon dehusking machine. It was further found that, the optimal performance (high efficiency and low likelihood of damage) occurs for a feed rate of approximately $11 \mathrm{~kg} / \mathrm{hr}$.

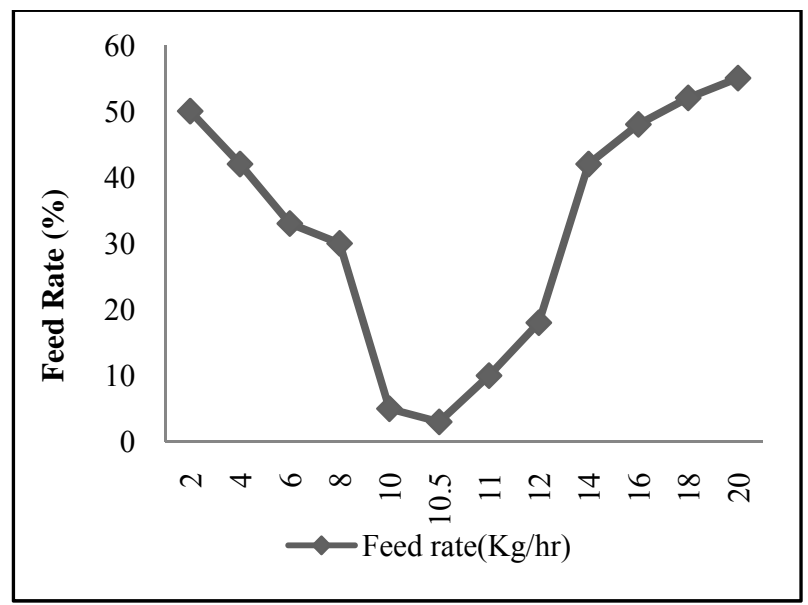

Fig. 2 Percentage of damaged seeds against feed rate. 


\subsection{Machine Capacity}

This explains the capacity of the machine in terms of the quantity of melon seeds shelled per unit time. Eq. (15) expresses the method of determining the machine capacity this context. Therefore;

$$
c_{m}=\frac{M s}{T}
$$

where, $C_{\mathrm{m}}=$ Machine Capacity $(\mathrm{kg} / \mathrm{hr})$;

$M_{\mathrm{s}}=$ Mass of seeds shelled (kg);

$T=$ Time taken to complete the operation (hr).

The study adopted Eq. (15) and the melon dehusking machine capacity was obtained as 196 $\mathrm{kg} / \mathrm{hr}$ that is, approximately $200 \mathrm{~kg}$ of melon seeds were shelled per hour.

\subsection{Critical Spreading Time}

It simply explains the time taken to spread the melon seeds for air drying process. After melon seeds have been treated in water, then, a spreading time of 30 minutes should be allowed as critical time. During this time, the melon seeds must have absorbed sufficient amount of water to adequately moisten the shells. To obtain this measure, a sample of 100 seeds weighing $11 \mathrm{~g}$ were washed with $30 \mathrm{~mL}$ of water and spread for air drying up to about 30 minutes before they were shelled. Fig. 3 presents the shelling efficiency of the machine as a function of the spreading time.

From Fig. 3, the relationship between shelling efficiency and the spreading time is presented; Research indicates that the short spreading time cases influence efficiency values that are generally in the $70 \%$ range. At higher values of spreading time, efficiencies rise to $85 \%$ and above. Similarly, there are indications that a spreading time of 30 minutes gave the highest shelling efficiency. Therefore, it suggests in this study that the melon seeds should be allowed to air dry for about 30 minutes in order to achieve optimal dehusking.

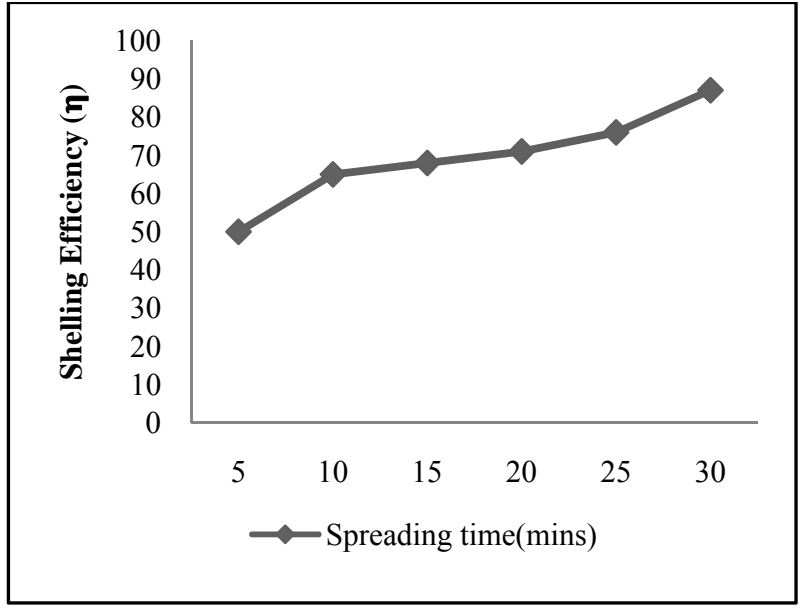

Fig. 3 Shelling efficiency against spreading time.

Table 2 Shelling efficiency variation with time using $10 \mathrm{ml}$ added water.

\begin{tabular}{llll}
\hline $\begin{array}{l}\text { Mass of } \\
\text { melon }(\mathrm{g})\end{array}$ & $\begin{array}{l}\text { Water added } \\
(\mathrm{mL})\end{array}$ & $\begin{array}{l}\text { Time of } \\
\text { soaking }(\mathrm{min})\end{array}$ & $\begin{array}{l}\text { Shelling } \\
\text { efficiency }(\%)\end{array}$ \\
\hline 11 & 10 & 5 & 69.35 \\
11 & 10 & 8 & 82.96 \\
11 & 10 & 10 & 77.53 \\
11 & 10 & 15 & 72.83 \\
\hline
\end{tabular}

5.5 Determination of Soaking Time for Optimal Dehusking

After the construction of the melon dehusking machine, series of tests were performed to determine the water soaking time that will give the highest shelling efficiency. Then, Table 2 showcases tested parameters that influence water soaking time on the shelling performance of this machine.

The acquired result from Table 2 showed that 8 minutes gave the best shelling efficiency in this study. Other findings in this case are as presented.

\section{Conclusions}

A melon dehusking machine was designed, constructed and tested and the results at every stage are shown. There are a lot of benefits derived from this study as it produces the invention of a melon dehusking machine to alleviate the suffering of man. Laborious tasks often associated with the process of melon dehusking through human efforts and time are completely eradicated. Detailed analyses have been 
performed in this pursuit and the outcomes have assisted in achieving optimal operation performance of melon dehusking process.

The results further suggest that both water soaking time and critical spreading time have effect on the shelling efficiency of the machine. However, it was deduced that a soaking time of 8 minutes and a spreading time of 30 minutes yield the best shelling result in comparison to the already existing melon dehusking machine which are often associated with incessant breakage during operation. For the accomplishment of good quality (fresh) melon dehusking, then, routine cleaning of the melon dehusking machine is desirable. These findings are quite innovative and could assist in the future research and development for agricultural and food scientists as well as engineering experts.

\section{References}

[1] Adekunle, A. S., Ohijecagbon I. O., and Olusegun, H. D. 2009. "Development and Performance Evaluation of Manually and Motorized Operated Melon Shelling Machine Using Impact Technique." (Journal of
Engineering Science and Technology Review) 2: 12-7.

[2] Akoh, C. C., and Nwosu, C. V. 1992. "Fatty Acid Composition of Melon Seed Oil Lipids and Phospholipids." J. Am. Oil Chem. Soc. 69: 314-7.

[3] Akpan, N. A. 2004. "Determination of the Force Required to Crack Melon Seed Shell by Static Loading at Different Moisture Content.” B.Eng. Dissertation, University of Uyo, Uyo, Nigeria.

[4] Egbuta, U., and Uyah, C. G. 2003. "Design, Fabrication of a Mechanical Method of Shelling and Separating Melon Seed by Centrifugal Impact Device". B.Sc. Dissertation, Obafemi Awolowo University, Ile-Ife, Nigeria.

[5] Makanjuola, G. A. 1972. "A Study of the Physical Properties of Melon Seeds." Journal of Agricultural Engineering Research 17 (1): 128-37.

[6] Gupta, J. K., and Khurmi, R. S. 2009. A Textbook of Machine Design. Eurasia Publishing House (Pvt) Ltd, 825-6.

[7] John, H., and Stephen, R. C. 1984. Mechanics of Machines: Elementary Theory and Examples. 2nd ed, E. Arnould Publishers, London.

[8] Odigboh, E. U. 1979. "Impact of Egusi Shelling Machine." Transaction of the ASAE 22 (5): 1264-9.

[9] Oyenuga, V. A., and Fetuga, B. L. 1975. "Some Aspects of Biochemical and Nutritive Value of the Water Melon Seeds (Citrullus Colocynthis).” J. Set. Food Agric. 26: 843-54. 


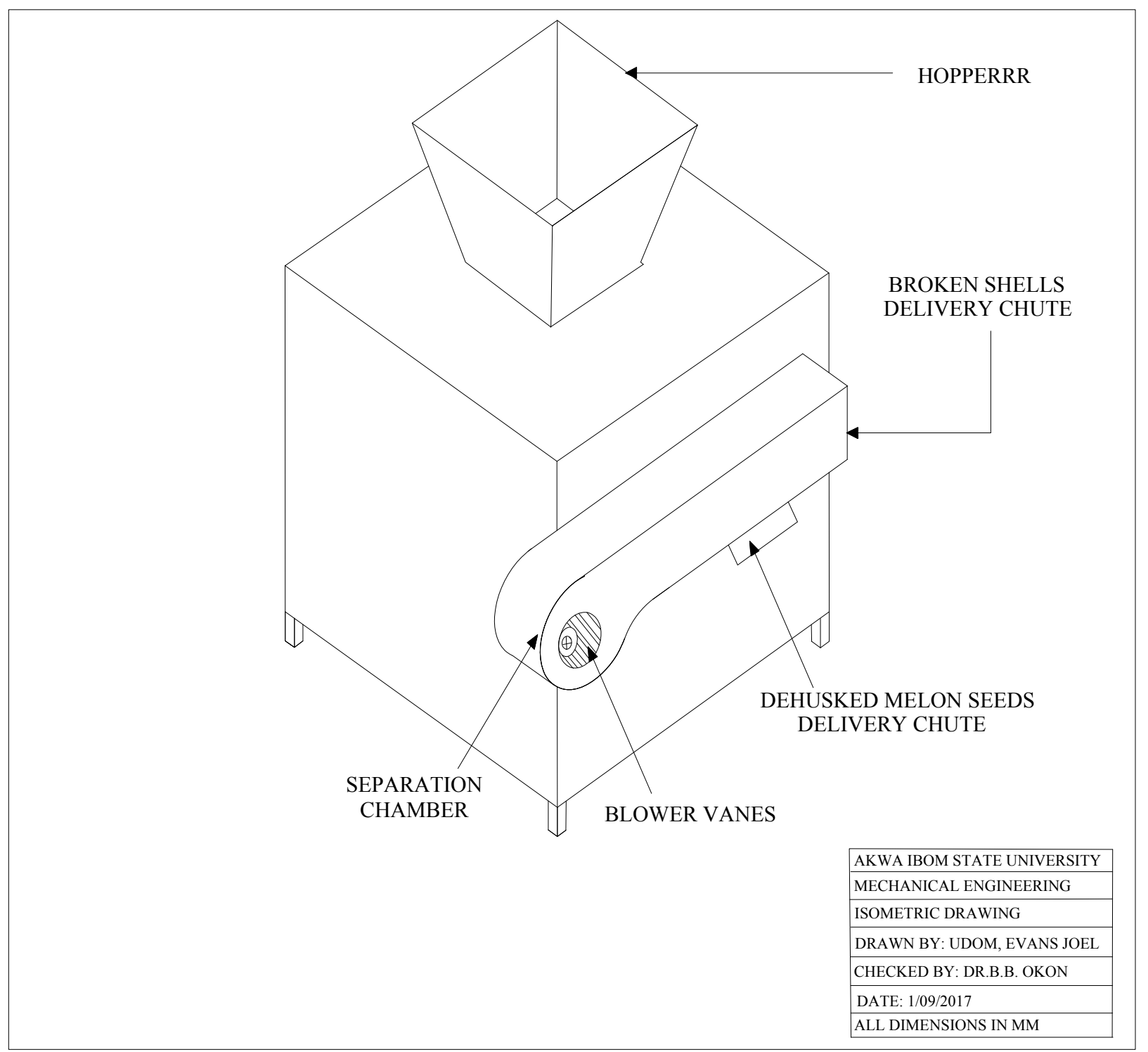

Fig. A Isometric drawing of the melon dehusking machine. 